\title{
Beginning of the ozone recovery over Europe? - Analysis of the total ozone data from the ground-based observations, 1964-2004
}

\author{
J. W. Krzyścin, J. Jaroslawski, and B. Rajewska-Więch \\ Institute of Geophysics, Polish Academy of Sciences, 64 Ks. Janusza Street, 01-452 Warsaw, Poland \\ Received: 15 November 2004 - Revised: 11 April 2005 - Accepted: 10 May 2005 - Published: 28 July 2005
}

\begin{abstract}
The total ozone variations over Europe $\left(\sim 50^{\circ} \mathrm{N}\right)$ in the period 1964-2004 are analyzed for detection of signals of ozone recovery. The ozone deviations from the longterm monthly means (1964-1980) for selected European stations, where the ozone observations (by the Dobson spectrophotometers) have been carried out continuously for at least 3-4 decades, are averaged and examined by a regression model. A new method is proposed to disclose both the ozone trend variations and date of the trend turnaround. The regression model contains a piecewise linear trend component and the terms describing the ozone response to forcing by "natural" changes in the atmosphere. Standard proxies for the dynamically driven ozone variations are used. The Multivariate Adaptive Regression Splines (MARS) methodology and principal component analysis are used to find an optimal set of the explanatory variables and the trend pattern. The turnaround of the ozone trend in 1994 is suggested from the pattern of the piecewise linear trend component. Thus, the changes in the ozone mean level are calculated over the periods 1970-1994 and 1994-2003, for both the original time series and the time series having "natural" variations removed. Statistical significance of the changes are derived by bootstrapping. A first stage of recovery (according to the definition of the International Ozone Commission), i.e. lessening of a negative trend, is found over Europe. It seems possible that the increase in the ozone mean level since 1994 of about $1-2 \%$ is due to superposition of the "natural" processes. Comparison of the total ozone ground-based network (the Dobson and Brewer spectrophotometers) and the satellite (TOMS, version 8) data over Europe shows the small bias in the mean values for the period 1996-2004, but the differences between the daily ozone values from these instruments are not trendless, and this may hamper an identification of the next stage of the ozone recovery over Europe.
\end{abstract}

Keywords. Atmospheric composition and structure (Middle atmosphere-composition and chemistry) - Meteorology and atmospheric dynamics (Climatology, Middle atmosphere dynamics)

Correspondence to: J. W. Krzyścin:

(jkrzys@igf.edu.pl)

\section{Introduction}

Stratospheric ozone depletion has been one of the major global scientific and environmental issues of the last century. In the mid-seventies scientists (Molina and Rowland, 1974, Rowland and Molina, 1975) suggested that man-made chlorofluorocarbons (CFCs) could be harmful to the ozone layer. The discovery of the ozone hole in the Southern Hemisphere (Chubachi, 1984; Farman et al., 1985), winter ozone losses over the Arctic (e.g. Brune et al., 1991), and statistically significant ozone depletion over the extratropical regions (e.g. WMO, 1989; Bojkov et al., 1990) strengthened the need of controlling the production of chemicals destroying the ozone layer. The first step in banning the production and use of CFCs was implemented by the Montreal Protocol, 1987. This, and six subsequent protocols, have helped to reduce emission of man-made ozone-depleting substances. Recent measurements of the trace gases content in the troposphere have shown that the total combined effective abundance of ozone-depleting compounds continues to decline slowly from the peak that occurred in 1992-1994. Observations in the stratosphere indicate that the total chlorine abundance is at or near a peak (WMO, 2003). Thus, ozone remains depleted in the mid and high latitudes of both hemispheres. The question arises as to when we are able to find the first sign of the ozone layer returning to its normal (pre1980 level) stage.

By examining predictions of chemistry-climate models, Weatherhead et al. (2000) estimated the time period required to detect turnaround in the ozone trend and the recovery timing. They found that recovery of total column ozone is expected first in the Southern Hemisphere near New Zealand, Southern Africa and Southern South America. We will be able to detect recovery in most regions of the world within the next 15 to 45 years, assuming full compliance with the Montreal Protocol and its amendments. However, lack of other ozone forcing factors, such as major volcanic eruptions or enhanced stratospheric cooling by the greenhouse gases, was assumed and appears to be essential for estimations of the recovery timing, yet is not possible to predict. 
In recent years a number of chemistry-climate models have been examined to simulate evolution of the stratosphere in the 21st century (e.g. Austin et al., 2003). It appears that an onset of the ozone recovery is very dependent on the model used. Differences in simulation of gravity and planetary waves and model resolution are basic sources of the differences in the models' predictions (Austin et al., 2003). For example, the Antarctic ozone recovery may begin any year within the period 2001-2008. The recovery could start later over the Arctic, i.e. any year within the period 2004-2019. Large interannual variability of the atmospheric dynamics over the Arctic and mid-latitudes provides an additional uncertainty to estimates of the recovery time. For example, disturbances in ozone due to the North Atlantic Oscillations (NAO) decadal changes could interfere with the ozone trend induced by the long-term variations in the chemical composition of the atmosphere (Schnadt and Dameris, 2003). It will result in an accelerated recovery of stratospheric ozone in the Northern Hemisphere.

The recent statistical analyses of the upper stratospheric ozone showed that its declining tendency has appeared weaker since the mid 1990s or even that there are signs of the ozone returning to its early 1970s level (Newchurch et al., 2003; Cunnold et al., 2004). In the upper stratosphere chemical reactions between chlorine and ozone mostly determine the ozone content there. However, in the lower stratosphere, where $80-90 \%$ of the stratospheric ozone resides, both chemical and dynamical factors can affect ozone depletion and restoration. Although chemical causes of the ozone depletion are relatively well known, the dynamical factors controlling long-term behaviour of the lower stratospheric ozone are not fully understood, thus, not well parameterized in the statistical and chemistry-climate models. It is difficult to separate the chemical and dynamical processes responsible for the ozone variations in the lower stratosphere. For example, cooling of the stratosphere due to well-mixed greenhouse gases, such as methane and water vapor, slows reactions destroying the ozone at mid-latitudes, and helps recovery. But changes in the thermal structure of the stratosphere also modulate the wind field, which controls the ozone transport and other long-lived chemicals important for the ozone chemistry. Thus, the atmospheric chemistry and transport are strongly coupled and the level of coupling is not well understood, precluding a precise estimation of the anthropogenic component of the total ozone trend.

In a press release by the International Ozone Commission (IOC), summarizing the Quadrennial Ozone Symposium held in Kos, Greece, June 2004 (presently available at web address: http://ioc.atmos.uiuc.edu/documents/ Statement-QOS2004.pdf) the following stages of the ozone recovery are defined: 1 - significant slowing in the downward trend of ozone, 2 - significant upward trend in the ozone time series that remains after removal of "natural" factors affecting the ozone layer, 3 - returning to pre-1980 ozone levels in the stratosphere. Whether or not stage 1 and 2 have been reached remains a subject of intense analysis. Here we would like to answer these questions by presenting a statisti- cal trend model capable of detecting the expected turnaround in the total ozone trend (Sect. 2). Statistical analyses will be applied to the total ozone time series by combining the daily total ozone measurements carried out at five selected European stations which have a reliable and long term data record (Sect. 3). In Sect. 4 we examine the difference between the total ozone values from the ground (the Dobson and Brewer spectrophotometer), and from the satellite (Total Ozone Mapping Spectrophotometer, TOMS, on board the Earth Probe satellite, Version 8 of the data) observing systems, to discuss how the quality of the ozone data may affect detection of the recovery stages. Concluding remarks are in Sect. 5.

\section{Statistical model}

Almost all previous estimates of the long-term ozone changes used a multiple regression technique which extracted a linear trend from the analyzed time series. The rate of ozone decline was taken as a slope of the straight line calculated in a regression model which also accounted for the ozone variations related (linearly) to the changes in the atmospheric circulation and external solar forcing (e.g. WMO, 2003). The ozone forcing factors due to global changes in the atmospheric dynamics were parameterized by indices of the quasi-periodical oscillations (e.g. QuasiBiennial Oscillations-QBO) and/or irregular long-term oscillations (e.g. NAO). The ozone fluctuations related to local dynamical processes affecting total ozone were taken as proportional to selected meteorological variables (temperature, potential vorticity, etc.). Recent analyses of the ozone data showed that its declining tendency has appeared weaker since the mid 1990s or even that there are the first signs of the ozone's return to its early 1970s level (Newchurch et al., 2003; Reinsel et al., 2004). Classical multiple regression models with a priori selected functional form of the ozone's long-term pattern (e.g. "hockey stick" pattern) and also supposing a linear response of ozone to the forcing factors, seem to be not well suited when searching for first steps of the ozone restoration.

Novel statistical techniques have been developed to describe the complexity of the long-term ozone behaviour in recent years. Reinsel et al. (2002) proposed a piecewise linear trend concept that was used in the calculation of the trend variability of the upper stratospheric ozone (Newchurch et al., 2003) and total ozone (Reinsel et al., 2004). Harris et al. (2001) proposed a regression method using a flexible tendency curve to describe the trend pattern in total ozone residuals after the elimination of "natural variations" from the observed total ozone. Here we present a model that is able to capture the long-term changes in total ozone without any a priori assumption on the functional form of the long-term pattern of the ozone change. The model uses the Multivariate Adaptive Regression Splines (MARS) technique and combines some recent ideas of trend models proposed by Harris et al. (2001) and Reinsel et al. (2002). 
The MARS technique was introduced by Friedman (1991) to describe a relationship between the dependent variable and the independent ones (the so-called regressors). It has been applied in a wide range of disciplines and now constitutes efficient tool belonging to canon of the data mining techniques (e.g. Lewis and Stevens, 1991; de Veaux et al., 1993a; Taliani et al., 1996; Finizio and Palmieri, 1998; de Gooijer et al., 1998; and Stephton, 2001). Recently Krzyścin applied MARS with additional autoregression terms to model trend in time series of the surface UV radiation (Krzyścin, 2003) and total ozone over Arosa (Krzyścin, 2004).

MARS competes very favorably with artificial neural network (NN) simulations that have become widely used in recent time series analyses. It appears that MARS could be applied instead of $\mathrm{NN}$ in a wide variety of applications. MARS simulations are found to be more interpretable and often more accurate than those by NN (de Veaux et al., 1993b, Steinberg, 2001). Like NN, MARS is effective when searching for complex structures in the data, such as nonlinearities and interactions. However, unlike NN, MARS is not a "black box", and provides models that are explainable to management.

MARS uses expansion in piecewise linear basis functions of the form $\left(x-x_{o}\right)_{+}$and $\left(x-x_{o}\right)_{-}$, where " $(\ldots)_{+}$" denotes the positive part (i.e. $\left(x-x_{o}\right)_{+}=x-x_{o}$ if $x>x_{o}$ and 0 otherwise) and "(...)_" means the negative part (i.e. $\left(x-x_{o}\right)_{-}=x_{o}-x$ if $x<x_{o}$ and 0 otherwise). If MARS uses $p$ explanatory variables (regressors), $F_{p}$, defined on $n$ discreet points $F_{i p}$, all basis functions $B F$ :

$B F=\left\{\left(F_{j}-F_{o j}\right)_{+},\left(F_{j}-F_{o j}\right)_{-}: F_{o j} \in\left(F_{1 j}, \ldots, F_{n j}\right): j=(1, \ldots, p)\right\}$ are examined as possible candidate functions in the regression. Thus, total number of such functions is $2 \mathrm{np}$. The model has the form:

$F(x)=\alpha+\sum_{m=1}^{M} \beta_{m} B F_{m}$

where each function $B F_{m}$ is a function in $B F$ or a product of two or more such functions, and $\alpha$ and $\beta_{m}$ are regression constants to be calculated by the penalized least-squares method. MARS carries out a trimming procedure to remove terms of Eq. (1), which do not remarkably contribute to the quality of fit. For an exhaustive description of the MARS techniques, references should be made to Friedman (1991) and Steinberg (1999).

Here we examine three models. In all models the trend term has a piecewise linear form representing the sum of the basis functions of time $t$. This assumption corresponds to Reinsel et al. (2002) description of a trend as two straight lines (the first one describing ozone depletion and the second one describing an increasing ozone tendency after the turnaround in the ozone trend). The MARS methodology is more general because a number of lines and dates for the trend turnarounds (the so-called knots) are not a priori assumed but appear as the model output.

The first model used, the most simplified one, is further denoted as a "linear" model. It parameterizes an influence of the regressor on total ozone, like in an ordinary least-squares method, as being proportional to this regressor:

$$
\begin{aligned}
O_{3}(t) & =\alpha+\sum_{i=1}^{M}\left\{\beta_{i,+}\left(t-t_{o i}\right)_{+}+\beta_{i,-}\left(t-t_{o i}\right)_{-}\right\} \\
& +\sum_{k=1}^{K} \gamma_{k} F_{k}(t)+\operatorname{Noise}(t) .
\end{aligned}
$$

The second model, further denoted as an "additive" model, uses a linear combination of functions $B F_{k}$ :

$$
\begin{gathered}
O_{3}(t)=\alpha+\sum_{i=1}^{M}\left\{\beta_{i,+}\left(t-t_{o i}\right)_{+}+\beta_{i,-}\left(t-t_{o i}\right)_{-}\right\} \\
+\sum_{k=1}^{K} \gamma_{k} B F_{k}+\text { Noise }(t)
\end{gathered}
$$

where, $\gamma_{k}$, the total ozone response to regressor $F_{k}$, is not constant for each regressor (like in Eq. (2) ), but may depend on the value of the regressor and thus is constant for the selected sub-ranges of the regressor.

The third model, the most sophisticated one, further denoted as a "nonlinear" model, comprises both linear combinations and products of two $B F s$ (thus the model has a nonlinear form assuming two-way interactions between regressors):

$$
\begin{aligned}
O_{3}(t) & =\alpha+\sum_{i=1}^{I}\left\{\beta_{i,+}\left(t-t_{o i}\right)_{+}+\beta_{i,-}\left(t-t_{o i}\right)_{-}\right\}+\sum_{j=1}^{J} \gamma_{j} B F_{j} \\
& +\sum_{l=1}^{L} \sum_{m=1}^{M} \delta_{l m} B F_{l} \bullet B F_{m}+\operatorname{Noise}(t),
\end{aligned}
$$

where $O_{3}(t)$ is the ozone monthly mean value in a month $t, \alpha, \beta_{(\ldots)}, \delta_{(\ldots)}$ are regression constants to be determined by the least-squares fit, and $\operatorname{Noise}(t)=\varphi$ $\operatorname{Noise}(t-1)+\operatorname{Random}(t)$, i.e. the noise represents an autoregression process with a 1-month lag, $\operatorname{Random}(t)$ represents the random term. The models' terms that remarkably influence the quality of fit remain in the regression. MARS carries out a trimming procedure to eliminate terms only slightly affecting the model fit.

A piecewise linear pattern for the ozone trend is a simple parameterization of the direction and magnitude of changes in the ozone. The "actual" long-term changes are probably not so sharp as those given by the piecewise linear trend. Reinsel et al. (2004) discuss that parameterization of the trend pattern as a "broken" line might be too simplified. A real trend should be represented by a smooth curve and the tendency revealed, after the turnaround (year 1996 was selected) was calculated, for a rather short period (less than 1 decade) and this might not be consistent with the "actual" long-term trend pattern.

We would like to address the question as to what extent the recent changes in ozone are a manifestation of a longer tendency in the data. We follow the concept of Harris et 
Table 1. The stations used in the analyses: location and first month with the results of the Dobson and Brewer spectrophotometer measurements.

\begin{tabular}{lrccc}
\hline Station & Longit.(W) & Latitude (N) & Dobson Start & Brewer Start \\
\hline Arosa & $9^{\circ} 40^{\prime}$ & $46^{\circ} 46^{\prime}$ & 01.1964 & 12.1988 \\
Belsk & $20^{\circ} 47^{\prime}$ & $51^{\circ} 50^{\prime}$ & 01.1964 & 06.1992 \\
Hohenpeissenberg & $11^{\circ} 01^{\prime}$ & $47^{\circ} 47^{\prime}$ & 01.1967 & 01.1984 \\
Hradec Kralove & $15^{\circ} 49^{\prime}$ & $50^{\circ} 10^{\prime}$ & 01.1964 & 01.1994 \\
Uccle & $4^{\circ} 21^{\prime}$ & $50^{\circ} 47^{\prime}$ & 01.1965 & 07.1983 \\
\hline
\end{tabular}

al. (2001) of deriving trends from the time derivatives applied to a smooth curve fitted to the total ozone time series which remains after the removal of the ozone fluctuations due to the regressors. A two step procedure is used to infer trend variability. A first step is a delineation of the initial trend pattern and random noise based on the above-mentioned regression models, taking into account the piecewise linear trend term and selected proxies explaining "natural" ozone variability. Harris et al. (2001) proposed a cubic polynomial to describe the long-term behaviour of ozone and used an ordinary leastsquares regression to find the "natural" components in the ozone data. Here, we do not define a specific function for the trend pattern, thus allowing MARS to find the best piecewise linear approximation of the trend pattern. Three versions of trend models are examined to find out if more sophisticated models are able to explain the much more variations in the ozone data compared to the linear model.

A second step is the examination of a bootstrap sample of smooth curves, $O_{3}^{*}$, fitted to representatives of the observed data (each time series comprises a trend term, the explained "natural" variations, and bootstrapped random noise) and representatives of the time series having extracted known "natural" variations (time series comprises a trend term and bootstrapped random noise, i.e. $\gamma_{j}=0$ in Eq. (5)):

$$
\begin{aligned}
O_{3}^{*} & =\left\langle\alpha+\sum_{i}^{I}\left\{\beta_{i,+}\left(t-t_{o i}\right)_{+}+\beta_{i,-}\left(t-t_{o i}\right)_{-}\right\}\right. \\
& \left.+\sum_{j=1}^{J} \gamma_{j} B F_{j}+\operatorname{Random}^{*}(t)\right\rangle
\end{aligned}
$$

where $\langle\ldots .$.$\rangle denotes a smoothing, \operatorname{Random}^{*}(t)$ represents a bootstrapped random noise term. For example, a candidate for the random noise in a selected January is randomly drawn from the time series of Random $(t)$ for all Januaries extracted by regression models in the first step of the trend procedure. To estimate changes in the mean ozone level and the ozone trend in selected time intervals we calculate the mean value and standard deviation from a sample of smooth curves that are fitted to the bootstrap representatives of the original data, and data having "natural" variations removed.

We use Locally Weighted Scatterplot Smoothing (LOWESS, Cleveland, 1979) as a smoother of the bootstrapped time series to cut off disturbances in the time series with a time scale of less than one decade (i.e. the LOWESS smoothing parameter $f=0.25$ has been assumed). The temporal differentiation (central differences) is applied to the smoothed time series and the change of the ozone mean level in the selected time interval is calculated as an integral (sum) of these derivatives over the interval. Application of temporal differentiation to the smoothed long-term component of the ozone time series was proposed by Harris et al. (2001) to reveal variations in the ozone trend. Here 1000 hypothetical time series of the ozone long-tem component are examined. For searching the initial stage of the ozone recovery we compare the ozone changes between the following years: 1970-1994 and 1994-2003. It appears that MARS selects 1994 (see next section) as the date for the turnaround in the ozone trend in the European total ozone. The next section contains the results of the trend analyses applied to the combined total ozone data from five European stations (located along $\sim 50^{\circ} \mathrm{N}$ ), having many decades the ozone observations by the Dobson spectrophotometers.

\section{Result of the trend model}

The data used are the daily means of total ozone measurements by the Dobson spectrophotometers at the sites listed in Table 1. The data were collected at the World Ozone and Ultraviolet Radiation Data Center (WOUDC) at Toronto, Canada. Here we examine data from stations providing longterm observations of total ozone over Europe along approximately a $50^{\circ} \mathrm{N}$ circle since January 1964 up to June 2004. Moreover, to quantify a long-term drift of the Dobson instrument due to calibration effects we make a cross-comparison of all total ozone data available for these sites (Sect. 4), also including the measurements by the Brewer spectrophotometers (see Table 1 for the onset of the Brewer measurements) and the total ozone mapping spectrophotometer (TOMS) on board of the Earth Probe satellite (since 1996).

We applied the trend models described in Sect. 2 to the total ozone time series, which contains the averaged values of the stations' monthly fractional deviations, i.e. differences between total ozone monthly means and the longterm (1964-1979) monthly means in percent of the long-term means. The analyzed time series and its long-term component (extracted by the LOWESS smoother) are shown in 
Fig. 1. It is seen that the ozone decline over Europe beginning at the end of the 1970s, lasted up to the early 1990s. It appears that the turnaround in the ozone's long-term pattern appears in 1994, and the present mean level of total ozone is $\sim 2 \%$ larger than that during ozone minimum years. Further in this section we would like to find out if this change in the long-term pattern can be seen as beginning of the ozone recovery and to what extent it is related to changes in the atmospheric dynamics.

The variables explaining the total ozone variations are similar to those used in the previous trend models:

- Indices of global circulation pattern: QBO effects are parameterized by the zonal component of wind at $50 \mathrm{hPa}$ and $30 \mathrm{hPa}$ over Singapore; ENSO - El Niño Southern Oscillations effects are described by the normalized surface pressure difference between Tahiti and Darwin; NAO impact on ozone is calculated using the normalized difference between surface pressure at Lisbon and Stykkisholmur (Iceland); zonal wind anomaly at $50 \mathrm{hPa}$ along a $60^{\circ} \mathrm{N}$ circle is an index of the strength of the winter polar vortex and potential ozone destruction in the polar and mid-latitudes regions following a cold polar vortex (recently used by Steinbrecht et al., 2003);

- Index of the external long-term forcing on ozone due to the 11-year changes in incoming solar radiation (the solar radio flux at $10.6 \mathrm{~cm}$ describes the pattern of the 11-year solar fluctuations);

- Index of the changes in the aerosols' loading in the stratosphere which influences the ozone layer via a heterogeneous reaction on the surface of the sulphate aerosols injected into the stratosphere during large volcanic eruptions (aerosol optical depth at $320 \mathrm{~nm}$ over $40^{\circ}-50^{\circ} \mathrm{N}$ region from the combined satellite and ground-based observations parameterizes the volcanic effect on ozone, data were prepared by the Surface Radiation Research Branch - SRRB of NOAA's Air Resources Laboratory and are presently available at http: //www.srrb.noaa.gov/research/aerdata.html);

- Meteorological variables describing the total ozone response to changes in the atmospheric conditions over selected stations; here temperature at levels 500, 50, and $10 \mathrm{hPa}$ have been selected from the temperatures profiles (comprising 16 levels from the surface up to $10 \mathrm{hPa}$ ) as a set of non-correlated ozone regressors, maximizing the variance explained by the model. Further in the text these variables are called local dynamical proxies. The temperature data are taken from the NCEP/NOAA reanalysis database (Kistler et al., 2001, data presently available at web address: http://nomad3. ncep.noaa.gov/ncep_data/index.html)

It should be mentioned that temperature cannot be treated as an ideal proxy for the dynamically driven variations in total ozone, i.e. being independent of the ozone variations. The

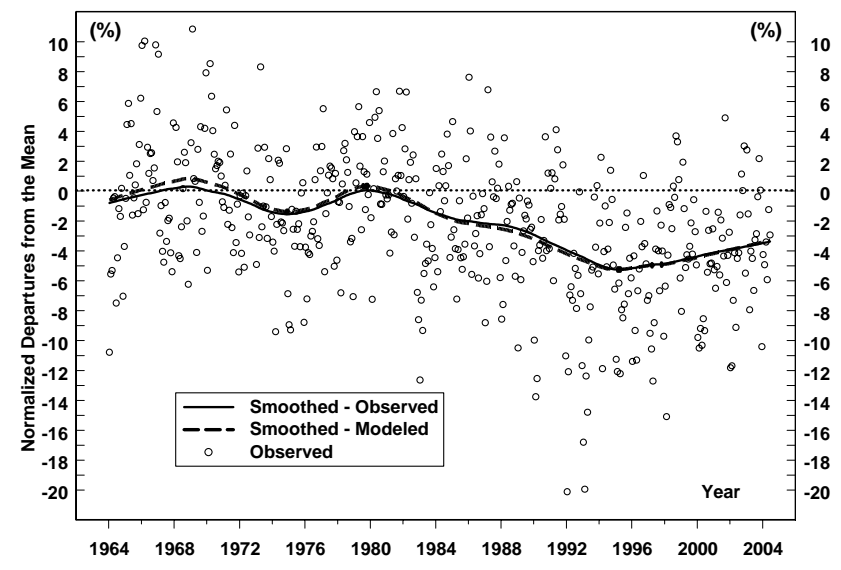

Fig. 1. Time series (1964-2004) of the averages of the monthly fractional deviations of total ozone over European stations (Arosa, Belsk, Hohenpeissenberg, Hradec Kralove, Uccle) with a longrecord of the Dobson spectrophotometer measurements. The solid and dashed curves represent the smoothed original and modeled total ozone, respectively.

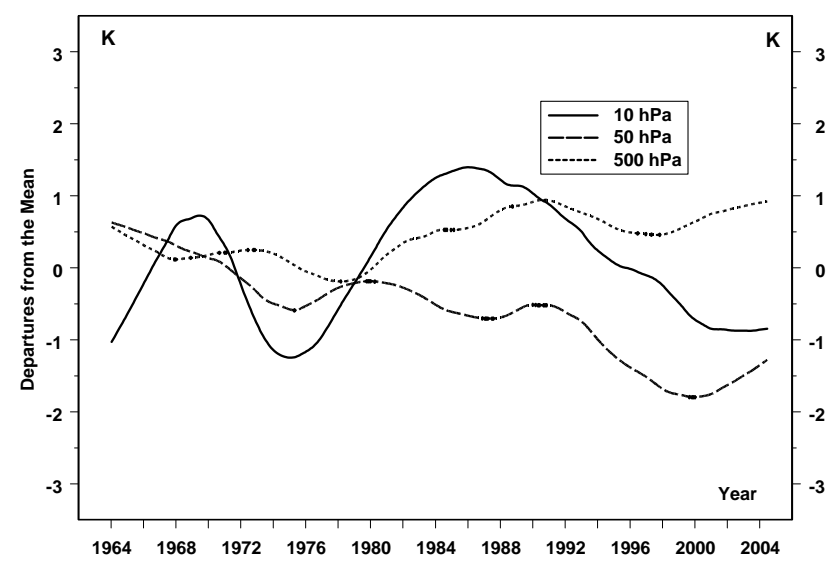

Fig. 2. Smoothed time series of the averaged temperature departures from the long-term (1964-1980) monthly means over the stations used in the analyses.

ozone decline itself yields cooling of the stratosphere, thus it seems possible that to some extent the ozone changes modulate the temperature pattern. The long-term components of the temperature time series extracted from the averaged temperature data over the stations are shown in Fig. 2. The warming of the troposphere and cooling of the stratosphere can be inferred from the temperature time series shown.

A detailed comparison shows (Shine et al., 2003) that the observed cooling in the Northern Hemisphere extratropical lower stratosphere is much larger than that calculated using the observed changes in the ozone and other greenhouse gases, including water vapour. Thus, it seems possible that the observed cooling includes a long-term component of unforced natural variability. This leads us to the necessity of examinating two classes of local dynamical regressors: original ones, containing the long-term variability component, and detrended ones. 
Table 2. Estimates of the ozone change in selected time intervals (\% of the long-term means) using the original time series (in columns "Tendency") and the time series having "natural" variations removed (in columns - "Trend") for models using detrended local proxies. The goodness of the model fit to the observed data is shown in the last two columns, where $\mathrm{R}^{2}$ denotes the explained percent of the variance of the original time series,; AIC represents the values of the Akaike's information criterion. The standard errors of the estimates are in parentheses.

\begin{tabular}{|c|c|c|c|c|c|c|}
\hline Model & $\begin{array}{l}\text { Tendency } \\
1970-1994\end{array}$ & 1994-2003 & $\begin{array}{l}\text { Trend } \\
1970-1994\end{array}$ & 1994-2003 & $\mathrm{R}^{2}(\%)$ & AIC \\
\hline Nonlinear & $-6.29(0.31)$ & $2.15(0.37)$ & $-4.60(0.29)$ & $-0.12(0.37)$ & 88.0 & 0.65 \\
\hline Additive & $-6.13(0.36)$ & $2.02(0.42)$ & $-4.62(0.34)$ & $-0.03(0.41)$ & 84.0 & 0.66 \\
\hline Linear & $-6.27(0.34)$ & $2.15(0.43)$ & $-4.90(0.34)$ & $0.24(0.42)$ & 83.7 & 0.67 \\
\hline
\end{tabular}

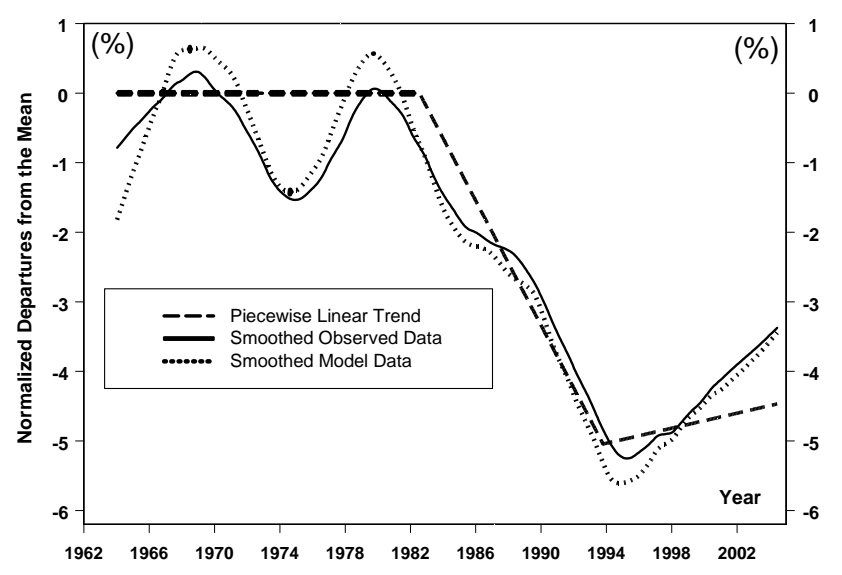

Fig. 3. Trend pattern revealed by the nonlinear model (dashed line) superposed on the smoothed original (solid curve) and modeled (dotted curve) time series of the European total ozone along $\sim 50^{\circ} \mathrm{N}$ circle.

For an ideal case the explanatory variables of a regression model are uncorrelated. Our proxies do not represent the case being partly interrelated, for example, tropospheric temperature in NH midlatitudes is affected by NAO, and lower stratospheric temperature by QBO. Thus, to eliminate an interference between the explanatory variables (sometimes it may lead to an artificial increase in the variance explained by a regression model), we transform the original variables to the principal components using a standard principal components analysis (PCA) which provides new proxies (uncorrelated) that are linear combinations of the original explanatory variables. This procedure also gives a smaller number of proxies, thus reducing the complexity of the multivariate sample by excluding the components that weakly affect the variance of the sample. Thus, functions $F_{k}$ and $B F_{k}$ in the models described in Sect. 2 are replaced by the principal components scores.

Figure 3 shows the piecewise linear approximation of the ozone trend pattern superposed on the observed and modeled long-term variations of the European total ozone. The results of the nonlinear model are shown. This model yields the lowest value of Akaike's Information Criterion - AIC (also see Table 2). The ozone depletion is most pronounced in the

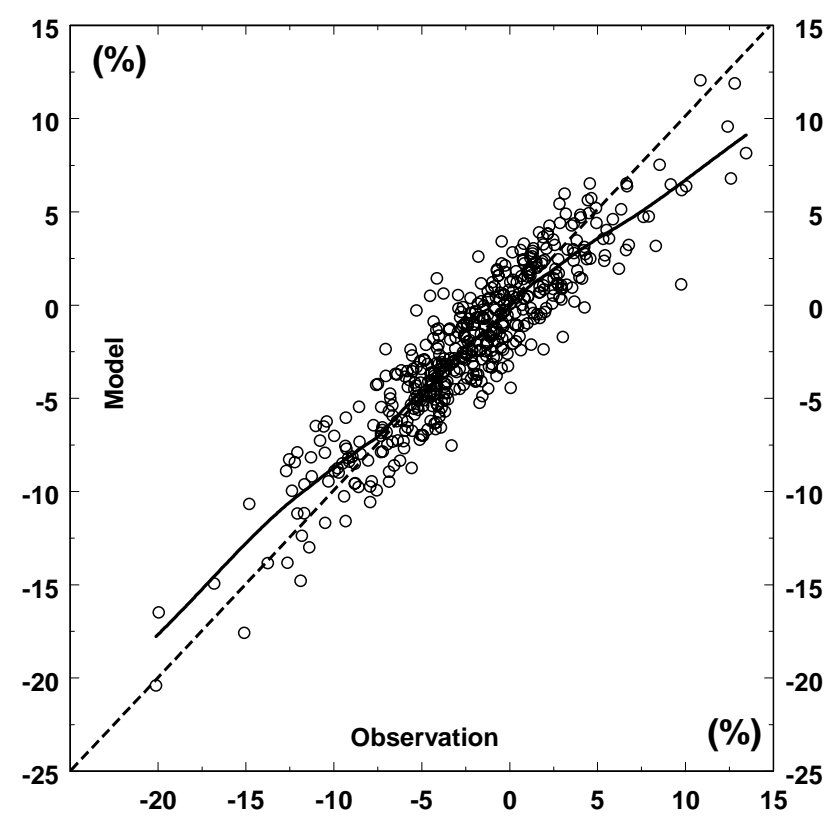

Fig. 4. Scatter plot of the observed-modeled monthly fractional deviations of the European total ozone along an $\sim 50^{\circ} \mathrm{N}$ circle. Solid curve represents the smoothed pattern.

1980s and the early 1990s, but around 1994 a kind of turning point in the trend pattern has happened. The dotted curve in Fig. 3 representing the smoothed model results, and the scatter plot of the model-observation differences (Fig. 4), illustrate that the trend model is able to reproduce both the longterm and monthly variations of the European total ozone data. The results of the linear and additive version of the model are almost similar (thus not shown here).

Table 2 summarizes the results of the regression models. The mean change in the total ozone (in percent of the 19641979 monthly means) and the mean change in the total ozone after removing "dynamically" driven disturbances from the original time series, are shown for the periods: January 1970-December 1993 and January 1994-December 2003. The results are presented in columns with the headers "tendency" and "trend", respectively. The date for the turnaround in the ozone's long-term pattern (i.e. January 1994) is taken 
as the time of appearance of the knot of the piecewise regression line during the 1990s (see Fig. 3). The mean values and their error estimates are derived from a sample of the 1000 bootstrap representatives of the observed total ozone and ozone time series, with "natural" variations removed. It should be noted that regardless of the regression models used, the ozone level at the end of 1993 is approximately $6 \%$ lower than the level in 1970. Thus, the rate of the decrease in the ozone mean level is $\sim 2.5 \%$ per decade in the period January 1970-December 1993. The mean ozone level at the end of the time series is $\sim 2 \%$ higher than that at the end of 1993 , i.e. the rate of increase in the ozone mean level is $\sim 2 \%$ per decade. These estimates are statistically significant at the $2 \sigma$ level. Thus, if this tendency is continuous for next few decades, the recovery will appear around 2024. By adding and subtracting the value of the 2- $\sigma$ error to the mean rate of the ozone increase since December 1993 (i.e. the rate is in the range $[1 \%, 3 \%])$, we can estimate that the earliest possible recovery date is $\sim 2017$ and the longest is $\sim 2044$, respectively. However, the rate of the total ozone increase since the turnaround date is a superposition of the ozone trend and dynamically driven long-term variations (parameterized by the regressors). It cannot be excluded that a future tendency in the driven long-term variations of total ozone will act in an opposite fashion to the recovery (due to changes in chemical composition of the atmosphere), yielding a slower ozone restoration rate, and thus delaying the recovery date.

The ozone change (see Table 2 for results with the "trend" header) calculated in the time series with the regressors' effects removed gives an estimate of the ozone's long-term behaviour caused by the chemical processes (changes in the atmosphere contamination by substances affecting ozone) and other yet unexplained long-term dynamical processes. The tendencies and trends shown in Table 2 appear to be almost the same for both models runs, using original and detrended local (temperature) proxies. We start from 10 explanatory variables and after the application of PCA to this set we end up with 8 components that explain about $95 \%$ of the variance of the starting sample of variables. Moreover, we calculate that the remaining two PCA components are not correlated with total ozone. Thus, PCA eliminates the trend temperature signal as being important for the models' output. The trend constitutes $\sim 75 \%$ of the declining tendency in the ozone data (see Table 2 for results with the "tendency" and "trend" headers). All models provide a statistically significant positive tendency ( $\sim 1-2 \%$ per decade) and a statistically insignificant ozone trend since January 1994. Taking into account a $-2 \sigma$ error of the trend estimate we can say that the trend is still negative, but the rate of ozone decline is much lower compared to that in the period 1970-1994. Thus, it is too early to announce a turnaround in the ozone trend. Comparing the tendency and trend values for the period 1994-2003 it can be hypothesized that an $\sim 2 \%$ increase of total ozone over Europe is due to the superposition of dynamical processes affecting the ozone layer in the last decade. It also seems possible that the ozone restoration since the ozone minimum at the beginning of the 1990s is in part due to a "natural"

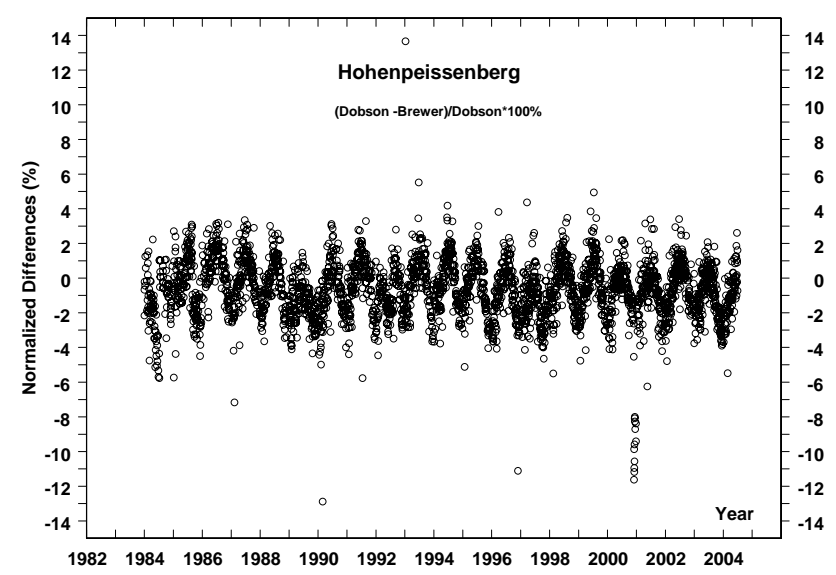

Fig. 5. Time series of the normalized differences between daily total ozone values by the Brewer and the Dobson spectrophotometers for Hohenpeissenberg, Germany, in the 1984-2004 period.

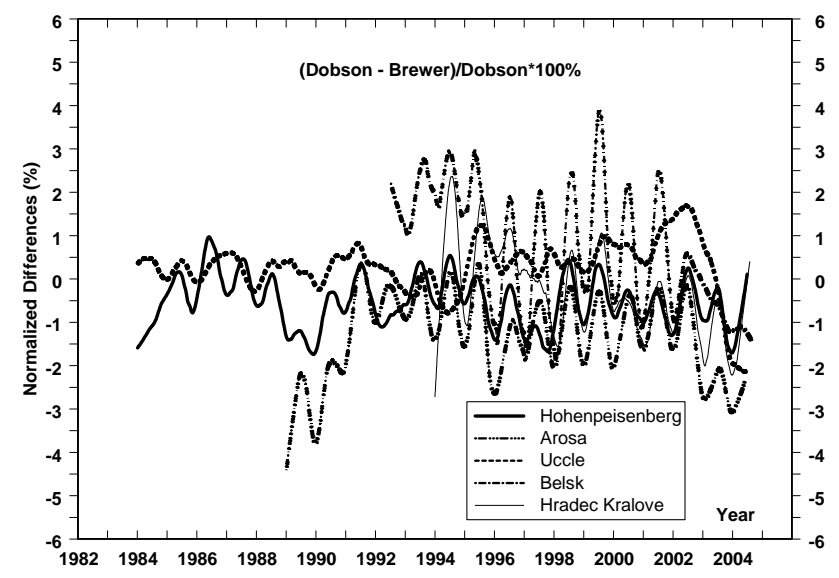

Fig. 6. Time series of the seasonal component of the normalized differences between daily total ozone by the Dobson and Brewer spectrophotometers for the European stations: Arosa, Belsk, Hohenpeissenberg, Hradec Kralove, Uccle.

cleaning of the atmosphere after the Mt. Pinatubo volcanic eruption.

\section{Quality of the total ozone network}

The total ozone data used in the trend analyses presented in Sect. 3 come from the measurements by the Dobson spectrophotometers. The European Dobsons frequently participated in the intercomparison campaigns with the traveling world standard (e.g. WMO, 1994), resulting in a homogenization of the ozone observations. The total ozone measurements by the Brewer spectrophotometers have been initiated at the beginning of the 1980s. Figure 5 shows the differences between the Brewer and Dobson daily total ozone in percent of the Dobson total ozone derived from the total ozone measurements carried out at Hohenpeissenberg for the period 1984-2004. The seasonal cycle in the normalized 


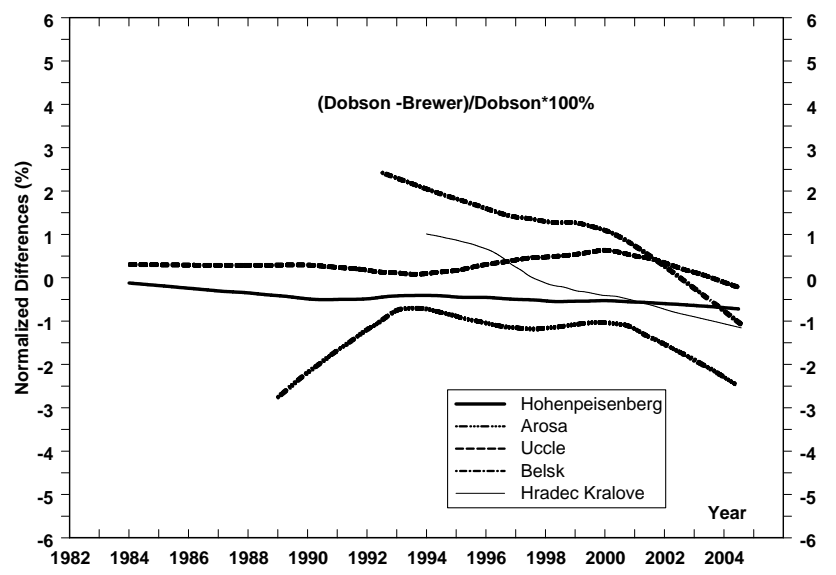

Fig. 7. The same as Fig. 6, but the long-term drift in the differences is shown.

differences is seen as the winter (summer) Dobson ozone appears lower (higher) than the Brewer ozone. The differences contain both a short- and long-term component, as shown in Figs. 6 and 7, respectively.

Recently, the seasonal differences between the instruments have been attributed to the retrieval of the Dobson total ozone, assuming a temperature at the ozone maximum level equal to $-46.3^{\circ} \mathrm{C}$ (Staehelin et al., 2003). In fact, the real temperature at the level of maximum ozone concentration is usually much lower (especially in winter) over the European stations, providing smaller absorption of the UV radiation by ozone and leading to an underestimation of the total ozone values. Using a correction of the Dobson spectrophotometer ozone for the real temperature at the level of ozone maximum ( $\sim 0.13 \%$ per one Kelvin degree of the temperature difference relative to $-46.3^{\circ} \mathrm{C}$; Komhyr et al., 1993) would yield a smaller difference between the instruments. However, van Roozendael et al. (1998) found that a similar correction should be applied to total ozone by the Brewer spectrophotometer. Degórska et al. (2004) discussed that the difference between Dobson and Brewer measurements remained practically unchanged after the correction had been applied to both instruments.

Taking into account the negative temperature trend in the stratosphere (see Fig. 2 for $2 \mathrm{~K}$ decrease of $50 \mathrm{hPa}$ temperature since 1980) and the Komhyr et al. (1993) correction factor, we can calculate that the ozone change in that period would be less negative by about $0.3 \%$, which is quite small when compared with the observed ozone depletion in that period $(6 \%)$. Thus, the application of the temperature correction to the Dobson data would not change the basic findings from Sect. 3. More important for the trend analyses is an appearance of the long-term oscillations in the normalized differences shown in Fig. 7. It is not clear what causes such long-term fluctuations. It seems possible that the Brewer instrument was not properly calibrated in the first years of operation (case of the Belsk's Brewer spectrophotometer). It cannot be excluded that recently an instrument drift has appeared in the ground-based network as a result of instrument aging or/and improper calibration. Because of the known deterioration of the TOMS instrument on board of the Earth Probe satellite, a cross comparison of the data could help a little when searching for possible sources of the longterm instruments' differences. Table 3 contains the results of a comparison of daily total ozone values from the groundbased and satellite observations. The results are divided into classes: the most reliable observations (direct Sun groundbased observations corrected for the temperature effects, and the satellite overpasses with a distance to the station of less than $50 \mathrm{~km}$ ), and all possible observations. The mean difference between the ground-based and satellite network is close to zero with the RMS error of 2-4\%. However, if the time series of the ground-based and satellite network are compared (Figs. 8 and 9), a kind of amplification of the differences between the ground-based and the satellite instrument is found since 2000, giving the impression that recent satellite data (TOMS version 8 ) should be treated with caution.

Fioletov et al. (2002) and Harris et al. (2003) have compared various total ozone time series from ground-based and satellite spectrophotometers. For zonal means over the NH mid-latitude band Fioletov et al. (2002) found differences between these data sets that varied over time, but generally were less than $1 \%$ (2 to 4 DU). Harris et al. (2003) analysis was based on low-pass filtered data and they found time varying differences between the data sets of $\sim 1 \%$ for midlatitudes regions.

The common pattern of the differences between the Brewer and satellite total ozone existing throughout the whole period of analysis (since beginning of the Earth Probe observations) for all stations leads to a suggestion that the recent Brewer measurements are more reliable (or more homogenized) than those by the Dobson spectrophotometers, and we may suppose that the negative trend in the normalized Dobson-Brewer differences over some stations that appeared since the late 1990s (Fig. 7) results from too low values (1$2 \%$ ) of total ozone from the Dobson measurements in recent years, for some stations. Thus, the signal of positive changes in the total ozone trend could be even more apparent in recent years, if we accounted for such instrumental changes.

\section{Conclusions}

Our analysis of the total ozone measurements from the European ground-based network, located along approximately a $50^{\circ} \mathrm{N}$ circle, supports stage 1 of the ozone recovery process (lessening of the ozone trend). It is too early to announce stage 2, because the trend in total ozone has been found to be statistically insignificant in the last decade. The uncertainty of the trend values is $\sim 1 \%$ per decade (at a $2 \sigma$ level). Thus, assuming that a positive trend in the ozone appeared in the mid 1990s, it would be around $1 \%$ for the most optimistic estimate of the recovery rate. In the opposite case, the most pessimistic estimate still gives negative $(\sim 1 \%$ per decade $)$ trend. It should be noted that our statistical estimates are 
Table 3. The normalized differences between the daily ozone values by the concurrent ground-based measurements (Dobson - "Dob" and Brewer - "Brew" spectrophotometers) and the Earth Probe TOMS overpasses ("Toms") for the selected European stations. The results are shown for the most reliable observations (ground-based data corrected for the temperature effects from the direct Sun measurements and close overpasses to the station, distance less than $50 \mathrm{~km}$ ) and all types of observations. The RMS errors are in parentheses.

\begin{tabular}{lccc}
\hline Station & \multicolumn{2}{c}{$\begin{array}{l}\text { Ground-Satellite Earth Probe }(\%) \\
\text { (Dob-Toms)/Dob }\end{array}$} & $\begin{array}{l}\text { Ground-Ground (\%) } \\
\text { (Brew-Toms)/Brew }\end{array}$ \\
Direct Sun + Temperature Corrected Data + Close Overpasses & \\
\hline Arosa & $1.7(2.4)$ & $3.0(2.8)$ & $-1.4(1.8)$ \\
Belsk & $2.3(3.9)$ & $2.3(3.7)$ & $0.7(3.6)$ \\
Hohenpeissenberg & $2.8(2.7)$ & $3.3(3.3)$ & $-0.6(1.7)$ \\
Hradec Kralove & $2.3(2.9)$ & $2.8(3.5)$ & $-0.3(2.1)$ \\
Uccle & $2.0(2.7)$ & $1.2(3.7)$ & $-0.2(1.5)$ \\
All Ground-Based and Satellite Data & & $-1.3(1.7)$ \\
\hline Arosa & $0.2(2.5)$ & $1.5(2.8)$ & $0.5(3.9)$ \\
Belsk & $1.1(4.2)$ & $1.0(4.2)$ & $-0.5(1.6)$ \\
Hohenpeissenberg & $1.3(2.7)$ & $1.7(3.2)$ & $-0.5(1.6)$ \\
Hradec Kralove & $0.9(2.9)$ & $1.7(3.5)$ & $0.4(2.5)$ \\
Uccle & $0.6(3.7)$ & $0.3(3.9)$ & \\
\hline
\end{tabular}

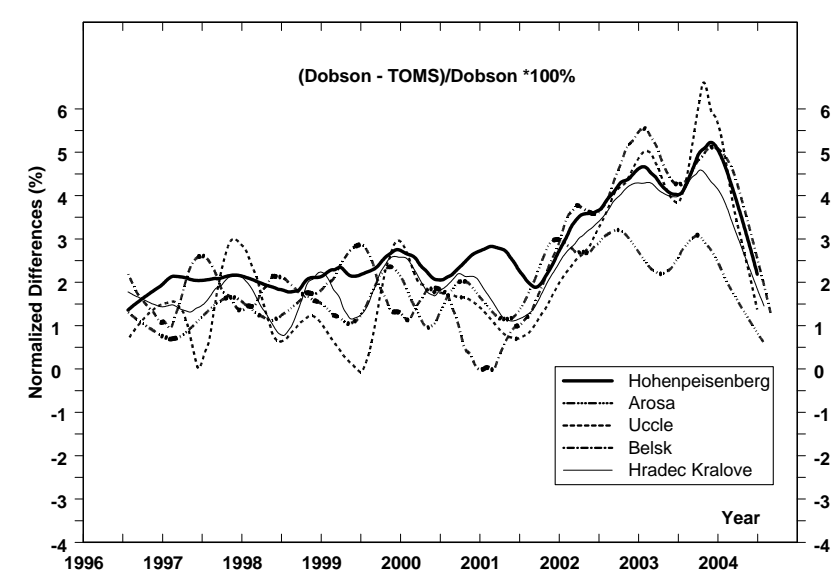

Fig. 8. Time series of the smoothed and normalized differences between daily total ozone values by the Dobson spectrophotometers and TOMS (on board of the Earth Probe satellite, version 8) overpasses for the selected European stations.

independent of the level of model complexity and method of treatment of the temperature proxies (detrended or original temperature data used for parameterization of the local weather conditions' impact on ozone). Here we calculated both the ozone tendency and the ozone trend, i.e. the characteristics of the long-term change of the total ozone level having included and removed "natural" ozone variations, respectively. Thus, the tendency represents a rate of ozone change comprising the anthropogenic and "natural" long-term component of ozone variability. The trend gives an estimate of an anthropogenic component, plus unknown long-term dynam-

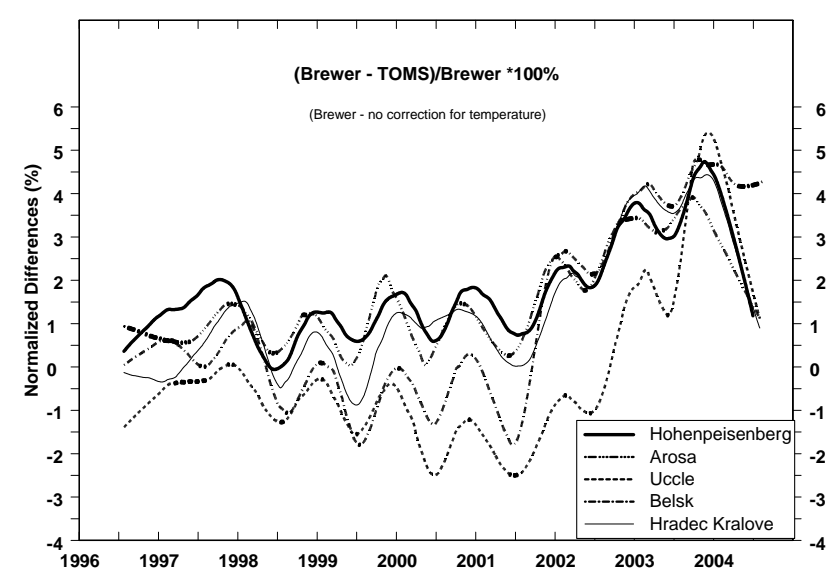

Fig. 9. The same as Fig. 8, but the differences are between the Brewer and TOMS total ozone values.

ical forcings. It may be hypothesized that an $\sim 2 \%$ increase the total ozone mean level in the last decade is due to a superposition of the dynamical processes affecting the ozone layer. It looks probable that an ozone positive tendency since the ozone minimum beginning in the 1990s is partly due to a "natural" restoration process after the lessening of the Mt. Pinatubo eruption effects on total ozone.

The statistical models used show that the unexplained variance is quite small (about $15 \%$ of the total variance) and has properties of random noise, i.e. the unknown ozone forcing factor cannot be linked to any quasi-periodical process in the atmosphere dynamics. Moreover, we found that total ozone responds linearly to the examined proxies (see small differ- 
ence between the explained variance by the models) and nonlinear interactions between the proxies help only a little to resolve the remaining variance. The statistical model cannot prove that all proxies used are really "natural" or that changes in total ozone and other trace gases' content in the atmosphere themselves modify the proxies. We hope that GCM will answer the key question as to what extent the stratospheric processes are forced by ozone (and other greenhouse gases) and how large is the "natural" variability of the lower stratosphere ozone as a superposition of various quasiperiodical and unperiodical dynamical processes. The level of coupling between the chemical and dynamical processes also needs to be identified.

The data quality is an important problem when searching for signs of ozone recovery. Comparison of the total ozone ground-based network (the Dobson and Brewer spectrophotometer) and the satellite (TOMS on board of the Earth Probe satellite. Version 8 of the data) data over Europe shows the small bias in the mean values for the period 1996-2004. However, what is more important is that the long-term component of the differences between the daily ozone values by these instruments reveals that the instrumental uncertainty of the ground-based spectrophotometers might be of the order of $1-2 \%$ and close to statistical errors of trends estimates for the period 1994-2003. Assuming that a positive trend of $1 \%$ per decade has appeared in the mid 1990s and will continue afterwards, we need many decades of observations to support the significance of such a trend. Thus, a continuation of the ozone observations is evidently needed to identify the second stage of the ozone recovery over Europe.

Acknowledgements. The study has been partially founded by the State Inspectorate for Environment Protection, Poland, under contract no. 74/2003/F. The statistical model used was developed under support of COST-726 action.

Topical Editor U.-P. Hoppe thanks a referee for his/her help in evaluating this paper.

\section{References}

Austin, J., Shindell, D., Beagley, S. R., Brühl, C., Dameris, M., Manzini, E., Nagashima, T., Newman, P., Pawson, S., Pitari, G., Rozanov, E., Schnadt, C., and Shepard, T. G.: Uncertainties and assessments of chemistry-climate models of the stratosphere, Atmos. Chem. Phys., 3, 1-27, 2003,

SRef-ID: 1680-7324/acp/2003-3-1.

Bojkov, R., Bishop, L., Hill, W. J., Reinsel, G. C., and Tiao, G. C.: A statistical trend analysis of revised Dobson total ozone data over Northern Hemisphere. J. Geophys. Res. 95, 9785-9807, 1990.

Brune, W. H., Anderson, J. G., Toohey, D. W., Fahey, D. W., Kawa, S. R., Jones, R. L., McKenna, D. S., and Poole, L. R.: The potential for ozone depletion in the Arctic polar stratosphere, Science, 252, 1260-1266, 1991.

Chubachi, S.: Preliminary result of ozone observations at Syowa station from February 1982 to January 1983, Mem. Natl. Inst. Polar Res., Spec. Issue Japan, 34, 13-19, 1984.

Cleveland, W. S.: Robust locally weighted regression and smoothing scatterplots, JASA, 74, 829-836, 1979.
Cunnold, D. M., Yang, E.-S., Newchurch, M. J., Reinsel, G. C., Zawodny, J. M., and Russel, J. M.: Comment on "Enhanced upper stratospheric ozone: Sign of recovery or solar effects?" by Steibrecht et al., J. Geophys. Res., 109(D14305), doi:10.1029/2004JD0004826, 2004.

de Gooijer, J. G., Ray B. K., and Krager, H.: Forecasting exchange rates using TSMARS, Journal of International Money and Finance, 17(3), 513-534, 1998.

Degórska, M., Krzyścin, J. W., Rajewska-Wiȩch, B., and Jarosawski, J.: Seasonal variation of the relative differences of total ozone measurements taken by the Dobson and Brewer Spectrophotometers at Belsk, Pub. Inst. Geophys. Pol. Acad. Sci, D64(371),73-76, 2004.

de Veaux, R., Gordon A., and Comiso, J.: Modeling of topographic effects on Antarctic sea-ice using Multivariate Adaptive Regression Splines, J. Geophys. Res.-Ocean, 98, 20 307-20319, 1993a.

de Veaux, R., Psichogios R., and Ungar, L. H.: A comparison of two nonparametric estimation schemes: MARS and Neural Networks, Computers in Chemical Engineering, 17, 819-837, $1993 b$.

Farman, J. C.: Gardiner, B. G., and Shanklin, J. D.: Large losses of total ozone in Antarctica reveal seasonal CLOx/NOx interaction, Nature, 315, 207-210, 1985.

Finizio, M. and Palmieri, S.: Non-linear modeling of monthly mean vorticity time changes; an application to the western Mediterranean, Ann. Geophys., 16, 116-124, 1998,

SRef-ID: 1432-0576/ag/1998-16-116.

Fioletev, V. E., Bodeker, G. E., Miller, A. J., McPeters, R. D., and Stolarski, R.: Global and zonal total ozone variations estimated from ground-based and satellite measurements: 1964-2000, J. Geophys. Res., 107, 4647, doi:10.1029/2001JD001350, 2002.

Friedman, J. H.: Multivariate Adaptive Regression Splines, The Annals of Statistics, 19, 1-50, 1991.

Harris, J. M., Oltmans, S. J., Tans, P. P., Evans, R. D., and Quincy, D. M.: A new method for describing long-term changes in total ozone, Geophys. Res. Lett., 28, 4535-4538, 2001.

Harris, J. M., Oltmans, S. J., Bodeker, G. E., Stolarski, R., Evans, R. D., and Quincy, D. M.: Long-term variations in total ozone derived from Dobson and satellite data, Atmosph. Environ., 37, 3167-3175, 2003.

Kistler, R., Kalnay, E., Collins, W., Saha, S., White, G., Woollen, J., Chelliah, M., Ebisuzaki, W., Kanamitsu, M., Kousky, V., van den Dool, H., Jenne, R., and Fiorino, M.: The NCEP-NCAR 50Year Reanalysis: Monthly Means CD-ROM and Documentation. Bull. Amer. Meteor. Soc., 82, 247-268, 2001.

Komhyr W. D., Mateer C. L., and Hudson R. D.: Effective BassPaur 1985 ozone absorption coefficients for use with Dobson ozone spectrophotometers, J. Geophys. Res., 98, 20, 451-20, 465, 1993.

Krzyścin, J. W.: Nonlinear (MARS) modelling of long-term variations of surface UV-B radiation as revealed from the analysis of Belsk, Poland data for the period 1976-2000, Ann. Geophys., 21, 1887-1896, 2003,

\section{SRef-ID: 1432-0576/ag/2003-21-1887.}

Krzyścin, J. W.: On the recovery of ozone over the NH midlatitudes: Statistical analyses of the long-term ozone measurements at Arosa, Proceedings of the Quadrennial Ozone Symposium, 18 June 2004, Kos, Greece, University of Athens, ed. Ch.S. Zerefos, 382-383, 2004.

Lewis, P. A. W. and Stevens, J. G.: Nonlinear modeling of time series using Multivariate Adaptive Regression Splines (MARS). J. Amer. Stat. Assoc., 86, 864-877, 1991. 
Molina, M. J., and Rowland, F. S.: Stratospheric sink for chlorofluoro-methanes: chlorine atom catalyzed destruction of ozone, Nature, 249, 810-814, 1974.

Newchurch, M. J., Yang, E.-S., Cunnold, D. M., Reinsel, G. C., and Zawodny, J. M.: Evidence for slowdown in stratospheric ozone loss: First stage of ozone recovery. J.Geophys. Res., 108(D16), 4507, doi:10.1029/2003JD003471, 2003.

Reinsel, G. C., Weatherhead, E. C., Tiao, G. C., Miller, A. J., Nagatani, R. M., Wuebbless, D. J., and Flynn, L. E.: On detection of turnaround and recovery in trend for ozone, J. Geophys. Res., 107(D10), doi:10.1029/2001JD000500, 2002.

Reinsel, G. C., Miller, A. J., Weatherhead, E. C., Flynn, L. E., Nagatani, R. M., Tiao, G. C., and Wuebbles, D. J.: Trend analysis of total ozone data for turnaround and dynamical contributions, The University of Chicago, Center for Integrating Statistical and Environmental Science, Rep.13, 2004.

Rowland F. S. and Molina, J. M.: Chlorofluoromethanes in the environment, Reviews of Geophysics and Space Physics, 13, 1-35, 1975.

Schnadt, C. and Dameris, M.: Relationship between North Atlantic Oscillation changes and an accelerated recovery of stratospheric ozone in the Northern Hemisphere, Geophys. Res. Lett. 30, doi:10.1029/2003GL017006, 2003.

Shine, K. P., Bourqui, M. S., De F. Forster, P. M., Hare S. H. E., Langematz, U., Braesicke, P., Grewe, V., Ponater, M., Schnadt, C., Smith, C. A., Haigh, J. D., Austin, J., Butchart, N., Shindell, D. T., Randel, J., Nagashima, T., Portmann, R. W., Solomon, S., Seidel, D. J., Lanzante, J., Klein, S., Ramaswamy, V., and Schwarzkopf, M. D.: A comparison of model-simulated trends in stratospheric temperatures. Q. J. Roy. Met. Soc. 129, 15651588, 2003.

Staehelin, J., Evans, R. D., Kerr J. B., and Vanicek, K.: Comparison of total ozone measurements of Dobson and Brewer spectrophotometers and recommended transfer functions, Global Atmospheric Watch/World Meteorological Organization Rep. 149, Geneva, 2003.
Steinberg, D.: An Introduction to MARS, San Diego, CA, Salford Systems, 1999.

Steinberg, D.: An alternative to Neural Networks: Multivariate Adaptive Regression Splines (MARS), PC AI, 15, 38-41, 2001.

Steinbrecht, W., Hassler, B., Claude, H., Winkler, P., and Stolarski, R. S.: Global distribution of total ozone and lower stratospheric temperature variations, Atmos. Chem. Phys. Discuss., 3, 34113449, 2003,

SRef-ID: 1680-7375/acpd/2003-3-3411.

Stephton, P.: Forecasting recessions: Can we do better on MARS, The Federal reserve Bank of St. Louis, Review, 83, 39-49, 2001.

Taliani, M., Palmieri, S., and Siani A.: Visibility: an investigation based on a multivariate adaptive regression spline techniques, Meteorol. Appl, 3, 353-358, 1996.

van Roozendael, M., Peeters, P., Roscoe, H. K., De Backer, H., Jones, A. E., Bartlett, L., Vaughan, G., Goutail F., Pommereau, J. P., Kyro, E., Wahlstrom, C., Braathen, G., and Simon, P. C.: Validation of ground-based visible measurements of total ozone by comparison with Dobson and Brewer spectrophotometers, J. Atmos. Chem., 29, 55-83, 1998.

Weatherhead, E. C., Reinsel, G. C., Tiao, G. C., Jackman, C. H., Bishop, L., Frith, S. M. H., DeLuisi, J., Keller, T., Oltmans, S., Fleming, E., Wuebbles, D., Kerr, J., Miller, A., Herman, . McPeters, J. R., Nagatani, R., and Frederick, J.: Detecting the recovery of total column ozone. J. Geophys. Res., 105, $22201-$ $22210,2000$.

World Meteorological Organization (WMO): Report of the International Ozone Trends Panel 1988. World Meteorological Organization Global Ozone Research and Monitoring Project - Report No., World Meteorological Organization, Geneva, Switzerland, Report 18, 1989.

World Meteorological Organization (WMO): Survey of WMOsponsored Dobson spectrophotometer intercomparisons, WMO Global Ozone Research and Monitoring Project, Report 19, (Ed.) Basher, R. E., 1994.

World Meteorological Organization (WMO): Scientific assessments of ozone depletion, 2002, WMO Report 47, Geneva, 2003. 